\title{
Phenomenology of Intuitive Judgment: Praecox-Feeling in the Diagnosis of Schizophrenia
}

\author{
Marcin Moskalewicz ${ }^{*}$, Michael A. Schwartz ${ }^{2}, \&$ Tudi Gozé \\ ${ }^{1}$ Department of Social Sciences, Poznan University of Medical Sciences; The Oxford Research \\ Centre in the Humanities (TORCH), University of Oxford; Res Publica Foundation, Warsaw \\ ${ }^{2}$ Department of Psychiatry and Behavioral Sciences, and Department of Humanities in Medicine, \\ Texas A\&M Health Science Center \\ ${ }^{3}$ Toulouse University Hospital; University of Wuppertal \\ *Corresponding author moskalewicz@gmail.com
}

29 January 2018; accepted 4 April 2018; published 30 September 2018.

\begin{abstract}
This paper argues that intuition plays a role in the diagnosis of schizophrenia and presents its phenomenological rationale. A discussion of self-assessment questionnaires and empirical studies in the clinical setting provides evidence that despite the prevalence of operational diagnosis, the intuitive judgment of schizophrenia continues to take place. Two related notions of intuitive diagnosis are presented: Minkowski's diagnostic by penetration and Rümke's praecox feeling. Further on, the paper explores and clarifies the phenomenology behind the praecox feeling. First, it is argued, intuitive diagnosis is neither a feeling nor an experience, but a typification operating at an implicit level. Second, it is not simply subjective as spatially it takes place in the in-between of the clinical interaction. Finally, it is not just momentary, but temporally extended, and, hence, partly reflective. The paper suggests that intuitive diagnosis requires critical testing on the side of the psychiatrist to either confirm or falsify it through reflective operations. In conclusion, the merits and shortcomings of intuitive vs. operational diagnosis are presented.
\end{abstract}

Keywords: affectivity; intuition; Minkowski; operational diagnosis; prereflective judgment; Rümke; typification.

\section{Introduction}

Is it possible to diagnose schizophrenia within the first minutes of interaction with a patient? And if it is possible, then how? Such an idea may seem preposterous these days given the all too well-known abuses of psychiatric patients in the $20^{\text {th }}$ century. Even if a 
few decades ago intuitive diagnosis was considered a reliable source for early detection of schizophrenia (Peters, 1973), today — so it is believed - it has lost its diagnostic validity. Certainly, it seems, it is an unreliable diagnostic compass when measured against the criteria of structural clinical interviewing (Ungvari, Xiang, Hong, Leung, \& Chiu, 2010). In this paper, we argue otherwise. Intuition, we will maintain, continues to play a role in the diagnosis of schizophrenia, and phenomenological philosophy provides its rationale. Despite the claim that clinical phenomenology lacks specificity, we assert that it is a valid source of clinical judgment, and, moreover, often an underpinning of the operationalized clinical interview.

Contemporary operational diagnostic criteria of schizophrenia stem directly from the third edition of the American Psychiatric Association's Diagnostic and Statistical Manual of Mental Disorders from 1980 (DSM-III) and the epistemological shift it implied. Despite its purported phenomenological backbone, DSM-III was based upon context-independent third-person data, and "phenomenological" only in the sense of a clear and unbiased description of the psychopathological appearance of particular mental disorders. From this perspective, schizophrenia, simply put, was a bundle of pathognomonic symptoms, that is symptoms specifically distinctive of that particular disease. The epistemological shift was a consequence of previous historical developments in psychiatric nosology. In particular, the numerous definitions of schizophrenia that fluctuated throughout the $20^{\text {th }}$ century, ranging from Kraepelinian and Bleulerian to psychodynamic and anti-psychiatric, were hardly reconcilable. The disagreements, confusions and inconclusiveness of debates on the ontological status of schizophrenia lead to the abandonment of competing individual definitions in favor of operational description, which was a pragmatic solution to the long-standing problem (McNally, 2012). Unintentionally, however, the operational approach of the DSMs led to the "death" of phenomenological psychopathology in the clinical setting (Andreasen, 2007). The contemporarily used, post-DSM III nosological concept of schizophrenia continues the tradition, and is intended to improve diagnostic reliability in research and in the clinic. Despite this fact, diagnoses of schizophrenia remain unreliable (Aboraya, 2007).

\section{The Praecox Feeling: Definition and Evidence}

Before the advent of operational diagnosis, it was quite common for psychiatrists to base their diagnoses on intuition. In this context, the popular notion of the praecox feeling was coined in 1941 by Dutch psychiatrist Henricus Cornelius Rümke (Rümke, 1990). The praecox feeling denoted a passive intuition of a clinician that a patient suffers from schizophrenia (the term "passive" was not used by Rümke in any precise phenomenological sense). The intuition was based upon a lack of directedness of contact, a loss of mutuality, and a certain stiffness of affect, all of which are supposed to indicate an insurmountable barrier between the patient and the clinician. In particular, Rümke claimed that the praecox feeling is felt even before speaking with the patient, and, hence, has nothing to do with the content of his thoughts. Moreover, according to Rümke, the praecox feeling is not 
searched for, never fully explicit, and thus not easily expressible in language. ${ }^{1}$ Rümke warned that symptoms alone do not warrant a label of schizophrenia if they do not refer to something essential that underlies them-something that the praecox feeling supposedly identified. That something is an elementary incomprehensibility of the patient stemming from his bodily posture, motor behavior, facial expressions, and overall lack of emotional contact. Rümke termed it a definite "un-understandability" of the patient. Finally, and most importantly, Rümke specified that this un-understandability is noticed not so much in the patient, but in the unease of the clinician himself. ${ }^{2}$

Before we move on towards a more philosophical explication of the praecox feeling, let us notice that despite being officially ignored by mainstream psychiatry, intuitive diagnosis in Rümke's spirit still takes place in clinical practice (Anonymous, 2001). Often, we suspect, it appears without conscious awareness of a psychiatrist and without one's understanding of the phenomenological underpinnings of the concept (Mundt \& Spitzer, 1999; Dörr, 2002; Vacek, 2005). Nonetheless, there is direct evidence that the praecox feeling plays a role in diagnosis. Two types of such evidence exist: the first concerns the prevalence of the praecox feeling among psychiatrists; the second is based on empirical studies in the clinical setting.

Regarding the first type of evidence, a survey conducted among West German psychiatrists in 1962 found that $85.8 \%$ had the praecox feeling, $57.9 \%$ found it reliable, and $25 \%$ thought it was more reliable than all other symptoms in establishing a diagnosis (Irle, 1962). ${ }^{3}$ According to the same questionnaire circulated in 1989 among 257 psychiatrists working in the New York Country District Branch of the American Psychiatric Association, 83.2 \% of them experienced the praecox feeling, $64.6 \%$ found it reliable, and $20.7 \%$ thought it was more reliable than all other symptoms (Sagi \& Schwartz, 1989). ${ }^{4}$ A current self-assessment questionnaire conducted among French psychiatrists found that $90.1 \%$ of psychiatrists acknowledge having experienced the praecox feeling, $74.1 \%$ find it reliable, and $12.3 \%$ believe it was more reliable than all other symptoms in diagnosing schizophrenia (Gozé, Moskalewicz, Schwartz, Naudin, Micoulaud Franchi, \& Cermolacce, 2018). ${ }^{5}$

\footnotetext{
${ }^{1}$ Our contemporary survey found that out of the psychiatrists who experience the praecox feeling, only $60 \%(21$ out of 35) in New York, 69\% (40 out of 58) in the United Kingdom, and 50.8\% (196 out of 386) in France, can articulate it in words (Moskalewicz, Schwartz, \& Gozé, 2017).

${ }^{2}$ Carp argued that the praecox feeling contains an element of being frightened by the dreadful isolation in which the patient exists - the more dreadful as one realizes that this is a human possibility. At the same time, the praecox feeling helps the clinician to retain an illusion of being fundamentally different from the other, and thus hide the “dark side of his own self” (Carp, 1971).

${ }^{3}$ There were 1196 responses with a $51.4 \%$ response rate.

${ }^{4}$ There were 257 responses with a $50.2 \%$ response rate.

${ }^{5}$ There were 463 responses with a $25.6 \%$ response rate.
} 
As far as empirical research is concerned, some of the theoretical insights about the praecox feeling have been substantiated. A study found that a deficient relationship with a patient is the second most reliable discriminator (reliability 0.86 ) in the diagnosis of schizophrenia and is thus a legitimate foundation of a diagnosis (Carpenter, Strauss, \& Muleh, 1973). A more recent study of 67 patients with acute psychotic symptoms and paranoid hallucinatory syndromes measured the intensity of the praecox feeling in an experienced therapist during a few minutes long interview focused upon the patients' current condition (Grube, 2006). Subsequently, a diagnostic assessment was performed and rated according to standardized diagnostic classifications (the World Health Organization's International Classification of Diseases and DSM-IV) by independent raters. The study found remarkably high concordance with the original intuitive diagnosis. ${ }^{6}$

There is also some indirect evidence based upon empirical research on the clinical encounter. Lowered contagion rates for yawning and laughing in persons with schizophrenia prove that their unconscious mirroring of the emotional actions of others is impaired (Haker \& Rössler, 2009). Such failed interpersonal resonance could explain the origin of the praecox feeling. A study found that a higher level of psychopathological symptoms in persons with schizophrenia (significantly different from analogous behaviors in depression) is associated with exhibiting more non-verbal "flight" behavior of their whole bodies, such as looking down or away, crouching, and frozen movement (Dimic et al., 2010). The latter takes place only during the first two minutes of interaction, reflecting Rümke's assumption of the immediacy of the praecox feeling. A review of 17 studies of non-verbal communication with patients with schizophrenia confirmed that fewer non-verbal behaviors inviting interaction (particularly pro-social facial expressions) are associated with increased negative schizophrenia symptoms, while positive symptoms correlate with heightened non-verbal behavior (Lavelle, Healey, \& McCabe, 2014).

\section{The Concept of Schizophrenia and the Origins of Intuitive Diagnosis in the Work of Minkowski}

The concept of schizophrenia first occurred in the work of Eugen Bleuler, and was later elaborated by Eugène Minkowski (Ashok, Baugh, \& Yeragani, 2012). This concept focused upon the so-called clinical core of the disorder, an idea similar to a contemporary insight of Alfred Binet and Théodore Simon about the essential feature of alienation (Binet $\&$ Simon, 1909). In the early $20^{\text {th }}$ century, the psychopathological debate about the ontological status of schizophrenia was central. While Emil Kraepelin's nosographic ambition was to classify mental pathologies according to a list of symptoms and longitudinal course

\footnotetext{
${ }^{6}$ Correct assignment, depending on the classification, was $86.6 \%$ for ICD-10 and 83.6 for DSM-IV, sensitivity 0.88 and specificity 0.82 for ICD-10, and sensitivity 0.84 and specificity 0.82 for DSM-IV. In addition, highly intensive praecox feeling ratings were significantly associated with family predisposition to schizophrenia. Only affective disturbances, and neither severity of illness, extrapyramidal side effects, gender nor duration of illness were correlated with the intensity of the praecox feeling.
} 
of illness, Bleuler introduced a notion pertaining to a clinical core- a characteristic $\mathrm{Ge}$ stalt (or a certain phenomenal reality) that reflected a radically altered mental life of the subject. Bleuler thus introduced the more essential notions of Spaltung and schizophrenic autism, the latter referring to a certain withdrawal to a fantasy life or detachment from reality. This clinical core was much more encompassing than the sum of clinical symptoms and was supposed to transpire through particular manifestations of illness (Parnas, 2011). ${ }^{7}$

The contribution of the aforementioned Polish-French psychopathologist Eugène Minkowski to this debate was crucial. Minkowski was trained in the Burghölzli Hospital with Bleuler and introduced the notion of schizophrenia in France. From Ludwig Binswanger, the founder of existential analysis in psychiatry, Minkowski borrowed the idea of diagnostic by feeling. However, in order to avoid any misunderstanding with the lay notion of feeling, he himself preferred the term "diagnostic by penetration." The latter distinguished this type of diagnosis from ordinary emotion or arbitrary impression. On the contrary, diagnostic by penetration was supposed to enable a skilled clinician to detect the essence of schizophrenic symptoms. According to Minkowski, Bleuler did not go far enough in his conceptualization of schizophrenic autism. Focusing on mental contents, he missed the key to understanding schizophrenia - the link between a person and her world. In his early La schizophrenie (1927), Minkowski put emphasis on ordinary schizophrenic activities in daily life. The clinical core of schizophrenia, and not simply its symptom, Minkowski claimed, is autism. It consists of a "loss of vital contact with reality." A person with schizophrenia "records" the data about the world but he does not feel the world (Minkowski, 1966, p. 305). She loses "resonance" with the world, but not (as is the case of Bleuler's autism) contact with the world. In consequence, her cognitive way of being in the world becomes problematic. She needs to explicitly reconstruct the normally implicit sense of experience, which makes her morbidly rational. The diagnostic by penetration is precisely a clinician's intuition that the patient has lost their vital contact with reality and has become alienated (Minkowski, 1927, p. 93).

\section{The Phenomenology of Intuitive Diagnosis}

We have seen, following Rümke and his predecessor, Minkowski, that intuitive diagnosis of schizophrenia is rather passive (meaning simply not consciously searched for) and immediate. It is a sense of incomprehensibility in the patient at an affective level. This elementary incomprehensibility transpires through the patient's symptoms. Also, it is not just

\footnotetext{
${ }^{7}$ The focus on structural changes of subjectivity faded away from current psychiatric nosology, which has led to reification of diagnostic categories. Only the contemporary view of schizophrenia as a self-disorder (that is, a basic, underlying abnormality concerning the self or ipseity) is indebted to the clinical core idea. A self-disorder is characterized by diminished self-affection (decline of subjectivity) and heightened awareness of normally tacit aspects of experience (hyperreflexivity) (Cermolacce, Naudin, \& Parnas, 2007; Sass \& Parnas, 2001). The notion of self-disorder is less focused on concrete symptoms and signs and more on the altered basic universal self behind the multitude of particular mental contents (Sass \& Parnas, 2003).
} 
an impression concerning the patient, but the psychiatrist as well, who feels awkward himself. Further on in this paper, we shall explore and clarify the phenomenology behind the praecox feeling. First, we will argue that it is not so much a feeling or an experience as a typification operating at an implicit level. Second, we will explain that the praecox feeling does not simply concern a subject typifying an object, since spatially it takes place in the in-between of the clinical interaction. Finally, we will show that the praecox feeling, even if originally immediate and momentary, can and should be reflectively apprehended and temporally extended - a process that will increase its clinical accuracy. We will thus look at the praecox feeling as a spatially and temporarily extended professional typification.

Logical empiricism presents the praecox feeling as merely subjective and, as such, lacking elementary scientific credibility (Hempel, 1965). However, if we interpret the praecox feeling not as a subjective feeling, but as a typification, the problem of the lack of credibility can at least in part disappear. A typification is a preconceptual skill analogical to many skills used by everyone in recognizing familiar objects of daily life. Typifications are essential constituents of any experience - they are immediate and presupposed by all other explicit categories (Husserl, 1975). In contradistinction to conceptualizations, typifications are skills we have without being aware of the rules we follow when using them. They operate below the level of explicit conceptualization and organize our field of experience as a whole, providing a meaningful context to thematize items within it. A concrete example of a common typification would be stopping a taxi on the street. It is a "skill" that does not require any explicit recognition of the general features of a taxi-such as a telephone number on the door or a specific model of the car if we are in London-that are compared with the approaching object. We do not infer, on the basis of a set of criteria, whether the car approaching is a taxi or not-we just notice it immediately (given we are familiar with taxis) and wave in order to stop it.

Regarding the diagnosis of schizophrenia, a typification is a skill that enables the recognition of the symptoms of schizophrenia as symptoms of schizophrenia, and not of something else. Differently than recognizing a taxi, such a skill requires specific and extensive training that makes one familiar with schizophrenia (Schwartz \& Wiggins, 1987b). All typifications are sedimented in a culture and context dependent (Fernandez, 2016). However, in typifying schizophrenia the context dependence and sedimentation are much stronger than in stopping a taxi. The familiarity with the clinical context as well as sedimentation in the clinical psychiatric culture are required. This is why both Minkowski and Rümke emphasize that only an experienced psychiatrist can use the praecox feeling. A properly trained psychiatrist tacitly typifying a person as suffering from schizophrenia should not be seen in analogy to someone stopping a taxi, but rather to an art connoisseur evaluating a work of art. It is a procedure far less common and much more context dependent and sedimented than stopping a taxi. When a skilled critic judges an abstract painting as being particularly precious, she does not follow a checklist of qualities describing an ideal, first-class work of art. Rather, she immediately apprehends the artistic accomplishment. Such an intuitive comprehension is possible thanks to her accumulated 
knowledge and practice at this particular skill, and it is the same with a skillful and experienced psychiatrist. ${ }^{8}$ Crucially, neither everyday typifications, nor rapid clinical diagnosis, nor the judgment of the work of art are scientific in nature. This does not mean, however, as we will also see later on, that their validity must be compromised.

If the praecox feeling is indeed a typification, then it has little to do with feeling or empathy (conventionally understood). In his later work, Rümke used the term Erlebnis (experience) instead of the term Gefühl (feeling). Through this shift in terminology, he tried to avoid any simple sensual connotations. The German term Erlebnis, moreover, as different from Erfahrung, indicates a lived experience, and not just an experience of an external object. The concept had been famously used by Wilhelm Dilthey to give an account of a humanistic kind of understanding as different from the natural scientific one. Also, Minkowski, we recall, used the term "diagnostic by penetration," and not by feeling. As for empathy, Rümke himself warned that high levels of empathy may actually preclude the possibility of the praecox feeling, when, for example, the physician has known the patient for a long time and does not find his awkward behavior disturbing (Rümke, 1990). More fundamentally, a phenomenological approach to intersubjectivity emphasizes that it transcends the emphatic encounter between the self and the other. The point of departure for intersubjectivity is a primordial connection between the subject, the other, and the world (Zahavi, 2001). It is rather the break of this (non-subjective) connection than any sort of subjective mode of particular consciousness of a clinician that constitutes the praecox feeling. This last remark brings us to the issue of the spatiality of intuitive diagnosis.

Seen in spatial terms, the praecox feeling does not indicate a change in the perception of the patient (even if we speak of some essential aspects of his presence and not just the symptoms of his illness), but a pre-reflexive transformation of phenomenologically understood intersubjectivity or affective tonality (Heidegger's Stimmung) between a patient and a psychiatrist. As such, it refers to implicit and minimal structures of self-world relatedness (Kraus, 1999). These structures are not "things" perceptible in the manner of objects of consciousness, such as particular gestures or facial expressions. If, again, the praecox feeling is a typification, it is not an ordinary typification of an external object, but one in which the whole intersubjective context is taken into account. The praecox feeling is a tacitly lived counterpart to the failure of affective attunement that takes place within an "atmosphere" shared by the two subjects (Tellenbach, 1968). Its origin, therefore, is not immediately localizable on the patient's side.

To give an account of such a pathological modification of lived intersubjective space, the Japanese psychopathologist Bin Kimura used the notion of interpersonal "Aida," translatable as "betweenness" (Odin, 1996, pp. 69-72). The principle of Aida that expresses the Japanese understanding of personhood is akin to Western phenomenological enactivist tradition of thinking (Kruger, 2013). Betweenness functions as an ontological category that precedes the emergence of self and non-self. This implies that the mental state of the

\footnotetext{
${ }^{8}$ Some researchers even suggest that this aesthetic ability could be expanded beyond diagnosis of schizophrenia to other mental disorders that have a specific "color" or "tone" (Bruni, Suppa, Scarpellini, \& Aguglia, 1994).
} 
other is not hidden from the senses, as a more traditional theory of mind would posit, but manifests itself immediately through bodily expressions and interactions. The point is that when the symptoms of schizophrenia are typified as symptoms of schizophrenia, they do not appear in the manner of objects referring to a physiological body of the patient. The same is true of what Parnas and Gallagher call a "rich" clinical diagnosis (Parnas \& Gallagher, 2015) - one in which the patient is seen as a gestalt in a wide sense of being embodied and embedded in his environment. Such a rich diagnosis is supposed to give a full understanding of the patient - and not just of his symptoms - as pointing to some causal referents of his disease. The praecox feeling shares this gestalt character of the rich diagnosis, except that at the very beginning it is rather immediate and tacit and does not require any conscious theorizing. The praecox feeling is a manifestation of primary disconnectedness at the very basic level of affective exchange that undergoes a peculiar metamorphosis (Gozé, Grohmann, Naudin, \& Cermolacce, 2017). This explains why it is not directly perceived by the examiner and may be a hidden factor involved in diagnosis. Thinking along these lines, some enactivists interpret the praecox feeling as an impossibility of affective interaction with the other, and not just a secondary frustration over the lack of such interaction. It is a failure of an understanding of the other at a very basic, prelinguistic and pre-reflective level (Varga, 2013). However, we believe, it is better to speak of the precariousness or bizarreness of an affective exchange rather than its impossibility. A total lack of such an exchange would result in a clearly autistic situation in which it would be indeed impossible to be disturbed by schizophrenia (Gozé \& Naudin, 2017).

Finally, to expand the analogy with the aesthetic judgment, the praecox feeling is not simply instantaneous, but requires a reflective extension in time. If the praecox feeling was nothing more than a momentary intuition, it could be quite arbitrary indeed. On the other hand, the reflective extension would increase its legitimacy. As any professional comprehension of art - in spite of the initial intuition that every expert reviewer would have-requires a second, and even a third, after-thought before it becomes a full-fledged aesthetic judgment, the praecox feeling should require some further reflection before it is established as a clinical judgment. In this sense, the praecox feeling that initially has the status of a tacit typification operating in the intersubjective space of affectivity requires some reflection to become a clinical diagnosis. Through this process, the unscientific typification becomes reflectively tested by evidence, becomes more explicit, and can be critically revised (Schwartz \& Wiggins, 1987b). But what exactly in the nature of this reflective process?

We have noticed that Rümke described the praecox feeling as a sense of definite un-understandability of the patient. Following Müller-Suur, let us notice that the primary intuition is rather of indefinite un-understandability, and it begs for subsequent clarification (MüllerSuur, 1961). If what happens in the clinical encounter with a schizophrenic person is not just the lack of an affective exchange (which could be immediately forgotten) but the bizarreness of the affective exchange, then the peculiarity of the encounter is being instantly thought of and reflected upon by a disturbed clinician. The initial sense of strangeness or bizarreness is confronted again within oneself - is this indeed what I am feeling? Then, the patient is seen once again, this time with a newly formed expectation of strangeness. This 
excludes the possibility of the patient having just an awkward moment in his behavior and coming back to normal a moment later. There might also be a quick search for disconfirming evidence which ultimately strengthens the validity of the initial impression. Only then, through the process of critical reflection, can the incomprehensibility of the patient which initially struck the psychiatrist become definite. Only if such a definite un-understandability remains after the process of clarification does the praecox feeling develop into a basis for a diagnosis. In this sense, the praecox feeling is neither indefinite nor definite, but extends between these two qualities. Vague during the first impression, it becomes more concrete during later reflective validation. To be sure, this whole process is quite rapid and may take no more than a few minutes of the interaction. It also takes place before, if not instead of, operational diagnosis by symptoms. Analogically, an explicitly conceptual operation of judging the given clinical case against the ideal type of schizophrenia (a procedure that is essentially different from operational diagnosis but similarly explicit) lies beyond this initial process. The reflective verification of the praecox feeling must not follow any ideal type of schizophrenia, despite the fact that such an ideal type may ultimately appear as a result of this feeling (Schwartz \& Wiggins, 1987a). But even if the praecox feeling does not reach the level of explicit diagnosis, the more self-critical and more thorough it is, the lower the possibility of false positive diagnosis further on.

\section{Conclusion}

In conclusion, we must emphasize that the praecox feeling does not exclude the possibility of operational diagnosis but denotes a more fundamental way of apprehending schizophrenia. Since it is very hard to express in psychiatric language what makes the patient's symptoms schizophrenic symptoms, the praecox feeling enables the clinician to see them as such. In addition, subtle pathology is not included in operationalized, third-person criteria to preclude misjudgment. The praecox feeling could potentially enhance early detection of schizophrenia and, in consequence, early therapeutic intervention (Grube, 2006). Despite the official rejection of intuitive diagnosis by mainstream psychiatry, we have seen that such a diagnosis not only takes place, but also can be phenomenologically explained. The validity of the praecox feeling is obviously different from operationalized, third-person diagnosis, but it does not imply that it is merely arbitrary and vague (or, in this respect, that it tells us more about the psychiatrist than about the patient). It is, of course, possible that the inability to form a bond may come from the inhibition of affective attunement on the psychiatrist's side. However, to reduce such a possibility, the praecox feeling should not be accepted at face value. It requires critical testing on the side of the psychiatrist to either confirm or falsify it through further reflective operation in which the incomprehensibility of the other becomes more definite. If the praecox feeling continues to be employed in the diagnosis of schizophrenia, this reflective (temporally extended) operation of concretization is needed to increase its potential of being an accurate judgment. The possibility of false positive classification and premature labeling cannot be a priori excluded, just as it is impossible to exclude the risk of an art connoisseur misjudging and overpricing a 
work of abstract expressionist art. Fortunately, neither art connoisseur nor psychiatrist operate in their judgment alone but are a part of a community of skillful experts subjecting their individual judgments to the evaluation of others. The evidence that their expert judgment is correct is often "imponderable," to use Wittgenstein's expression, but again, it should not diminish its validity. Nonetheless, the reliability of such a judgment is of a different sort than that of operational diagnosis. If we, however, deprive psychiatry of expertise, and trade the remnants of its humanistic aspects for the increase of reliability, we may soon find ourselves asking why schizophrenia is a mental illness at all.

\section{References}

Aboraya, A. (2007). The reliability of psychiatric diagnoses. Psychiatry, 4(1), 22-25.

Andreasen, N. C. (2007). DSM and the death of phenomenology in America: An example of unintended consequences. Schizophrenia Bulletin, 33(1), 108-112.

https://doi.org/10.1093/schbul/sbl054

Anonymous. (2001). That 'praecox feeling.' Psychiatric Bulletin, 25(7), 275-275. https://doi.org/10.1192/pb.25.7.275

Ashok, A. H., Baugh, J., \& Yeragani, V. K. (2012). Paul Eugen Bleuler and the origin of the term schizophrenia. Indian Journal of Psychiatry, 54(1), 95-96. https://doi.org/10.4103/00195545.94660

Binet, A., \& Simon, T. (1909). Définition des principaux états mentaux de l'aliénation. L'année Psychologique, 16, 61-66. https://doi.org/10.3406/psy.1909.3788

Bruni, P., Suppa, M., Scarpellini, M. G., \& Aguglia, F. (1994). Praecox gefuehl in medicina. Minerva Psichiatrica, 35(3), 193-195.

Carp, E. A. D. E. (1971). Über das Praecox- und Hysteriegefühl. Psychotherapy and Psychosomatics, 19(4), 232-239. https://doi.org/10.1159/000286321

Carpenter, W. T., Strauss, J. S., \& Muleh, S. (1973). Are there pathognomonic symptoms in schizophrenia? An empiric investigation of Schneider's first-rank symptoms. Archives of General Psychiatry, 28(6), 847-852. https://doi.org/10.1001/archpsyc.1973.01750360069010

Cermolacce, M., Naudin, J., \& Parnas, J. (2007). The “minimal self” in psychopathology: Re-examining the self-disorders in the schizophrenia spectrum. Consciousness and Cognition, 16(3), 703-714. https://doi.org/10.1016/j.concog.2007.05.013

Dimic, S., Wildgrube, C., McCabe, R., Hassan, I., Barnes, T. R. E., \& Priebe, S. (2010). Non-verbal behaviour of patients with schizophrenia in medical consultations - a comparison with depressed patients and association with symptom levels. Psychopathology, 43(4), 216-222. https://doi.org/10.1159/000313519

Dörr, O. (2002). El papel de la fenomenología en la terapéutica psiquiátrica con especial referencia a la esquizofrenia. Revista Chilena de Neuro-Psiquiatría, 40(4), 297-306. https://doi.org/10.4067/S0717-92272002000400002 
Fernandez, A. V. (2016). Phenomenology, typification, and ideal types in psychiatric diagnosis and classification. In R. Bluhm (Ed.), Knowing and acting in medicine (pp. 39-58). Lanham, MD: Rowman \& Littlefield International.

Gozé, T., Grohmann, T., Naudin, J., \& Cermolacce, M. (2017). New insight into affectivity in schizophrenia: From the phenomenology of Marc Richir. Psychopathology, 50(6), 401-407. https://doi.org/10.1159/000481516

Gozé, T., Moskalewicz, M., Schwartz, M. A., Naudin, J. Micoulaud Franchi, J-A., Cermolacce, M. (2018). Is "Praecox feeling" a phenomenological fossil? A preliminary study on diagnostic decision making in schizophrenia. Schizophrenia Research. https://doi.org/10.1016/j.schres.2018.07.041

Gozé, T., \& Naudin, J. (2017). Discussing Rümke's “Praecox Feeling” from the clinician's experience of schizophrenic contact. Psicopatologia Fenomenológica Contemporânea, 6(2), 112-123.

Grube, M. (2006). Towards an empirically based validation of intuitive diagnostic: Rümke's "praecox feeling" across the schizophrenia spectrum: Preliminary results. Psychopathology, 39(5), 209-217. https://doi.org/10.1159/000093921

Haker, H., \& Rössler, W. (2009). Empathy in schizophrenia: Impaired resonance. European Archives of Psychiatry and Clinical Neuroscience, 259(6), 352-361.

https://doi.org/10.1007/s00406-009-0007-3

Hempel, C. G. (1965). Aspects of scientific explanation. New York, NY: Free Press.

Husserl, E. (1975). Experience and Judgment: Investigations in a Genealogy of Logic. (J. S. Churchill \& K. Ameriks, Trans.). Evanston, IL: Northwestern University Press.

Irle, G. (1962). Das "Praecoxgefuehl” in der Diagnostik der Schizophrenie. Archiv Für Psychiatrie Und Nervenkrankheiten, Vereinigt Mit Zeitschrift Für Die Gesamte Neurologie Und Psychiatrie, 203, 385-406.

Kraus, A. (1999). The significance of intuition for the diagnosis of schizophrenia. In M. Maj \& N. Sartorius (Eds.), Schizophrenia (pp. 47-49). Chichester, UK: John Wiley \& Sons.

Kruger, J. (2013). Watsuji's phenomenology of embodiment and social space. Philosophy East and West, 63(2), 127-152. https://doi.org/10.1353/pew.2013.0016

Lavelle, M., Healey, P. G. T., \& McCabe, R. (2014). Nonverbal behavior during face-to-face social interaction in schizophrenia: A review. The Journal of Nervous and Mental Disease, 202(1), 47-54. https://doi.org/10.1097/NMD.0000000000000031

McNally, K. (2012). Definitions of schizophrenia, 1908-1987: The failed essentialism. Theory \& Psychology, 22(1), 91-113. https://doi.org/10.1177/0959354310377821

Minkowski, E. (1927). La Schizophrénie. Paris, France: Edition Payot.

Minkowski, E. (1966). Traité de psychopathologie. Paris, France: Presses Universitaires de France.

Moskalewicz, M., Schwartz, M. A., \& Gozé, T. (2017). [Expert judgment in the clinical diagnosis of schizophrenia]. Unpublished survey data.

Müller-Suur, H. (1961). Das sogenannte Praecoxgefuehl. Fortschritte Der Neurologie-Psychiatrie, $29,145-152$. 
Mundt, C., \& Spitzer, M. (1999). Psychopathologie heute. In Psychiatrie der Gegenwart 1 (pp. 3-44). Berlin, Germany: Springer. https://doi.org/10.1007/978-3-642-60174-3_1

Odin, S. (1996). The social self in Zen and American pragmatism. New York: State University of New York Press.

Parnas, J. (2011). A disappearing heritage: The clinical core of schizophrenia. Schizophrenia Bulletin, 37(6), 1121-1130. https://doi.org/10.1093/schbul/sbr081

Parnas, J., \& Gallagher, S. (2015). Phenomenology and the interpretation of psychopathological experience. In L. J. Kirmayer, R. Lemelson, \& C. A. Cummings (Eds.), Re-visioning psychiatry: Cultural phenomenology, critical neuroscience, and global mental health, 65-80. Cambridge, UK: Cambridge University Press. https://doi.org/10.1017/CBO9781139424745.006

Peters, U. H. (1973). Wortfeld-Störung und Satzfeld-Störung: Interpretation eines schizophrenen Sprachphänomens mit strukturalistischen Mitteln. Archiv Für Psychiatrie Und Nervenkrankheiten, 217(1), 1-10. https://doi.org/10.1007/BF02552827

Rümke, H. C. (1990). The nuclear symptom of schizophrenia and the praecoxfeeling. Translated and with an Introduction by J. Neeleman. History of Psychiatry, 1(3), 331-341. https://doi.org/10.1177/0957154X9000100304

Sagi, G. A., \& Schwartz, M. A. (1989). The "praecox feeling" in the diagnosis of schizophrenia; A survey of Manhattan psychiatrists. Schizophrenia Research, 2(1-2), 35. https://doi.org/10.1016/0920-9964(89)90071-6

Sass, L. A., \& Parnas, J. (2001). Phenomenology of self-disturbances in schizophrenia: Some research findings and directions. Philosophy, Psychiatry, \& Psychology Psychology, 8(4), 347-356. https://doi.org/10.1353/ppp.2002.0027

Sass, L. A., \& Parnas, J. (2003). Schizophrenia, consciousness, and the self. Schizophrenia Bulletin, 29(3), 427-444.

Schwartz, M. A., \& Wiggins, O. P. (1987a). Diagnosis and ideal types: A contribution to psychiatric classification. Comprehensive Psychiatry, 28(4), 277-291. https://doi.org/10.1016/0010440X(87)90064-2

Schwartz, M. A., \& Wiggins, O. P. (1987b). Typifications: The first step for clinical diagnosis in psychiatry. The Journal of Nervous and Mental Disease, 175(2), 65-77.

Tellenbach, H. (1968). Geschmack und Atmosphäre. Salzburg, Austria: Otto Müller Verlag.

Ungvari, G. S., Xiang, Y.-T., Hong, Y., Leung, H. C. M., \& Chiu, H. F. K. (2010). Diagnosis of schizophrenia: Reliability of an operationalized approach to "praecox-feeling." Psychopathology, 43(5), 292-299. https://doi.org/10.1159/000318813

Vacek, J. (2005). O intuici a intuitivní diagnostice v psychiatrii. Česká a Slovenská Psychiatrie, 101(4), 218-223.

Varga, S. (2013). Vulnerability to psychosis, I-thou intersubjectivity and the praecox-feeling. Phenomenology and the Cognitive Sciences, 12(1), 131-143. https://doi.org/10.1007/s11097-0109173-z

Zahavi, D. (2001). Beyond empathy: Phenomenological approaches to intersubjectivity. Journal of Consciousness Studies, 8(5-7), 151-167. 